\title{
Capital Saving Towards Achievement of Inter-Temporal Sustainable Development
}

\author{
MOHAMMED EBRAHIM HUSSIEN and CHAMHURI SIWAR
}

Institute for Environment and Development (LESTARI), National University of Malaysia (UKM), Malaysia

http://dx.doi.org/10.12944/CWE.9.1.05

(Received: January 04, 2014; Accepted: February 21, 2014)

\begin{abstract}
Since the time immemorial, saving has been considered as a major driving factor for the prosperity of household and the development of countries. Traditionally, the inter-temporal concept of saving is limited to one's life span irrespective of next generation. Development is, however, not considered as sustainable unless it has inter-generational and societal stand. This paper intends to show how capital saving is crucial factor for sustainable economic development. Thus the paper develops capital saving model in which the saved capital transferred throughout generation. The model derived from 'Infinite-Horizon Model' developed by Ramsey-Cass-Koopmans. The derived model infers that the pressure of population growth in a geometric progression can be minimized through inter-generational capital saving. The model shows the simultaneous proportional growth of capital and population for continuous generation.
\end{abstract}

Key words: Inter-temporal saving, Capital, Sustainable

Economic Development, Infinite generation.

\section{INTRODUCTION}

Various growth and development models have been evolving since the time of classical economics, but the factors of development and priority issues of a nation vary throughout school of thoughts. The past schools of economic thought gave a due emphasis for economic development marginalizing the non-economic issues. They compromised the trade-off relationship between economic development and natural resource depletion. According to their view, growth is 'first' and environment is 'later', since economic growth reduces poverty. Although economic growth is necessary condition for poverty reduction yet is not sufficient condition for solve income inequality problem (Veron 2001). Besides, there is an essence of short-run dimension which might lead to less consideration for future generation. For instance, long-run is not concern of Keynesians due to full of uncertainty; and their problem solving models deals only on short-term cases as it was stated by Keynes
"The long run is a misleading guide to current affairs. In the long run we are all dead"(Keynes1923).

Furthermore, the world population is projected to continue increasing well into the next century. Recently, approximately, $80 \%$ of the world's populations live in which half or more of economically active labor-force engaged in agricultural sector. That is where agriculture is leading sector in economy. This area is featured by poor economic level, high population growth rate, and low agricultural productivity. According to the projection, the prevailing world population will be doubled in the coming four decades, while the agricultural land becoming less and less due to population pressure and urbanization. Such increasing population and urbanization will clearly put a good deal of pressure on natural resources and the environment, and will pose especially severe problems on developing nations. 
Nations are striving to assure economic development. Working to eradicate or alleviate major macroeconomic problems such as poverty and income inequality. These macro-problems can be solved through growth and development phenomenon. But to realize economic development, natural and environmental resources must be utilized. In doing so, the stock of resources will be depleted. Since it lacks societal concept, this type of achievement through trade-off relation between environmental resource and economic development is no longer sustainable (Nihoul 1998).

The idea of scarcity of resources and unlimited human wants make most economists to be pessimistic in predicting the future. Thomas Malthus (1798) has shown the issue of resource scarcity in his discussion about population theory and environmental limit. Similarly, David Ricardo (1815) emphasized on land capital, discussed the trade-off between population and productivity arguing resources are limited. Classical economists used total production curve to show diminishing returns. However, technical and technological progress has shifted the production curve which in turn leads to growth (Mebratu 1998). Although technical and technological improvement leads to growth; the economic sustainability in terms of macro-economic growth is necessary condition but not sufficient condition for sustainable development, particularly in developing countries. Researchers also argued that population growth is also needed for the technological growth and economic growth in near future (Alam et al. 2009; 2011; Molla et al. 2013).

In the World Commission on Environment and Development (WCED) report on "Our Common Future" (1987) (also known as Brundt land Report), sustainable development is defined as "development which meets the needs of the present without compromising the ability of future generations to meet their own needs" (Boggia and Cortina 2010). Furthermore, it is about maintaining natural (i.e. ecological) bases of economic development. The emphasis on material growth maximizes resource use and consumption, thereby maximizing entropy (disorder) that leads to unsustainable development. That means that sustainable development is the development which minimizes the increase in net global disorder and aims at securing the productivity of non-renewable natural capitals and conserving all species of fauna and flora (Faucheux et al. 1995).

Traditional economic schools of thoughts are failed to economize some social and environmental capitals that are vital for sustainable development of a nation. Besides, their models lack the societal view for sustainable generation. This shortcoming leads to the call for the new architect of economic model which has potential to transform "business as usual" attitude of socio-economic activities to the inter-generational societal development model. Accordingly, the notion of sustainable development emerged to regard the need of current generation without jeopardizing the interest of next generations. In doing so, numerous schemes and initiatives has been suggested and implemented. In line with this paradigm, the paper proposes the inter-temporal capital saving as one of driving tools towards achieving sustainable economic development.

\section{Inter-temporal Capital Saving Model}

The 'Infinite-Horizon Model'was developed by Ramsey (1928), which was further developed by Cass (1965) and Koopmans (1965). Infinite-Horizon model can be named as RCK model too. The model used to discount only the overall consumption function of households to the present value vis- $\alpha$-vis budget constraint of one generation. The inter-temporal concept of RCK model is about present consumption and saving (for future consumption by the saver himself). However, here inter-temporal idea is the present consumption of current generation and the saving (for the consumption of future generations). In this model, saving is transcendental concept beyond the life span of one generation. In other words, it is the intact amount of wealth to be inherited by the subsequent generations.

Using RCK function as a base model, here we derive the consumption function for continuous (infinite) generation considering the following assumptions:

No capital depreciation (adopted from overlapping generation model) 
Stock of natural resource kept constant throughout generation (adopted from Daly's theory of sustainable economic development)

The households'consumption maximization forRCKmodel is:

$$
\begin{aligned}
& \int_{t=0}^{\infty} e^{-R(t)} c(t) e^{(m+g) t} d t \leq k(0)+ \\
& \int_{t=0}^{\infty} e^{-R(t)} w(t) e^{(m+g) t} d t
\end{aligned}
$$

Where, $m=$ household (labor) growth rate, $g=$ technological growth rate, $\mathrm{R}(\mathrm{t})=$ real interest rate at time $t$

That is, lifetime consumption $\leq$ initial wealth/capital + lifetime labor income. Simply we can demonstrate it as:

$$
\mathrm{C} \leq \mathrm{K}+\mathrm{Y}
$$

Where, $C$ is consumption, $\int_{t=0}^{\infty} e^{-R(t)} c(t) e^{(m+g) t} d t$, $K$ is initial wealth $(K(0))$ and $Y$ is labour income $\int_{t=0}^{\infty} e^{-R(t)} w(t) e^{(m+g) t} d t$

Base equation for one generation, it can be rearranged as:

$$
\mathrm{C}-\mathrm{K}-\mathrm{Y} \leq 0
$$

However, in order to secure sustainability, it is necessary condition to maintain at least equal amount of wealth to that of what was inherited initially. Consequently, it can be derived the consumption model which is compatible with sustainability concept as follows:

$$
\mathrm{C}_{0}-\mathrm{K}_{0}-\mathrm{Y}_{0} \leq \mathrm{K}_{1}
$$

Where, $\mathrm{K}_{\mathrm{o}}$ initial wealth, $\mathrm{K}_{1}$ wealth to be inherited by the subsequent generation.

This assumption corresponds to Daly's (1989) "weak sustainability" condition. In which he states that the constant sum of the resource stock must be transferred to the future generation in order to realize sustainable economic development.

Assuming $\mathrm{K}_{0}$ is equal to $\mathrm{K}_{1}$; it can develop the general formula for infinite generation as follows:

$$
\begin{aligned}
& C_{0}-K_{0}-Y_{0} \leq K_{1} \\
& C_{1}-Y_{1} \leq K_{1}+K_{1}
\end{aligned}
$$

Since, $\mathrm{K}_{0}$ and $\mathrm{K}_{1}$ are assumed to be equal, model for first generation:

$$
\begin{aligned}
& \mathrm{C}_{1}-\mathrm{Y}_{1} \leq 2 \mathrm{~K}_{1} \\
& \mathrm{C}_{2}-2 \mathrm{~K}_{2}-\mathrm{Y}_{2} \leq 2 \mathrm{~K}_{2}^{2} \\
& \mathrm{C}_{2}-\mathrm{Y}_{2} \leq 2 \mathrm{~K}_{2}+2 \mathrm{~K}_{2}
\end{aligned}
$$

Model for Second generation:

$$
\begin{aligned}
& \mathrm{C}_{2}-\mathrm{Y}_{2} \leq 4 \mathrm{~K}_{2} \\
& \mathrm{C}_{3}-4 \mathrm{~K}_{3}-\mathrm{Y}_{3} \leq 4 \mathrm{~K}_{3} \\
& \mathrm{C}_{3}-\mathrm{Y}_{3} \leq 4 \mathrm{~K}_{3}+4 \mathrm{~K}_{3}
\end{aligned}
$$

Model for Subsequent generation:

$$
\mathrm{C}_{3}-\mathrm{Y}_{3} \leq 8 \mathrm{~K}_{3}
$$

Thus the general formula is:

$$
\begin{aligned}
& C_{n}-Y_{n} \leq 2^{n} K_{n} \\
& \int_{t=i}^{\infty} e^{-R(i)} c(i) e^{(m+g) i} d t- \\
& \int_{t=i}^{\infty} e^{-R(i)} w(i) e^{(m+g) i} d t \leq 2^{i} k(i)
\end{aligned}
$$

Where, $g$ is technological growth rate and $R(i)$ is real interest rate at generation. Where ' $n$ ' denotes nth generation and $\mathrm{K}_{0}$ represents initial wealth of first generation.

Furthermore, the Keynesian consumption function to derive the inter-temporal functional relationship between saving and capital is as follows:

$$
C=Y_{d}-S \text { or } Y=C+S
$$

Where, $C$ denotes for consumption, $Y_{d}$ disposable income and $S$ represents savings.

Here, it assumes simple macro-economic model with no government as an economic factor. 
But from the rearrangement of RCK base model, equation (2), and equation (9):

$$
\begin{aligned}
& \mathrm{C}=\mathrm{Y}-\mathrm{S} \text { and } \mathrm{C} \leq \mathrm{K}+\mathrm{Y} \\
& \mathrm{Y}-\mathrm{S} \leq \mathrm{K}+\mathrm{Y} \\
& \mathrm{Y}-\mathrm{S} \leq \mathrm{K}_{\mathrm{o}}+\mathrm{Y}
\end{aligned}
$$

Where, $\mathrm{K}_{\mathrm{O}}$ is the inherited initial wealth by current generation,

$$
-\mathrm{S} \leq \mathrm{K}_{\mathrm{o}}
$$

This implies that the amount to be saved and maintained to be transferred to the subsequent generations is equal to the initially inherited capital, . In addition, the negative sign implies "intertemporal" concept in which is wealth of current generation whilst the current will be the initial capital for the next generation.

\section{Inter-temporal Sustainability Model}

The concept of the model is applicable for the capital savings of both consumers and producers. The prevailing consumers are assumed to save the financial and physical capital they own whilst producers mainly assumed to save natural capitals in order to transfer the intact wealth for the subsequent generations.

Natural capital, physical capital, human capital, and social capital are considered factors determining sustainable development. In the case of natural resources, neoclassical analysis uses the egalitarian principles of Rawls (1971) in describing the criteria under which real consumption can be kept constant at a steady level over time regardless of the exhaustion of nonrenewable resources (Spangenberg et al., 2002; Marjan W., 1996).

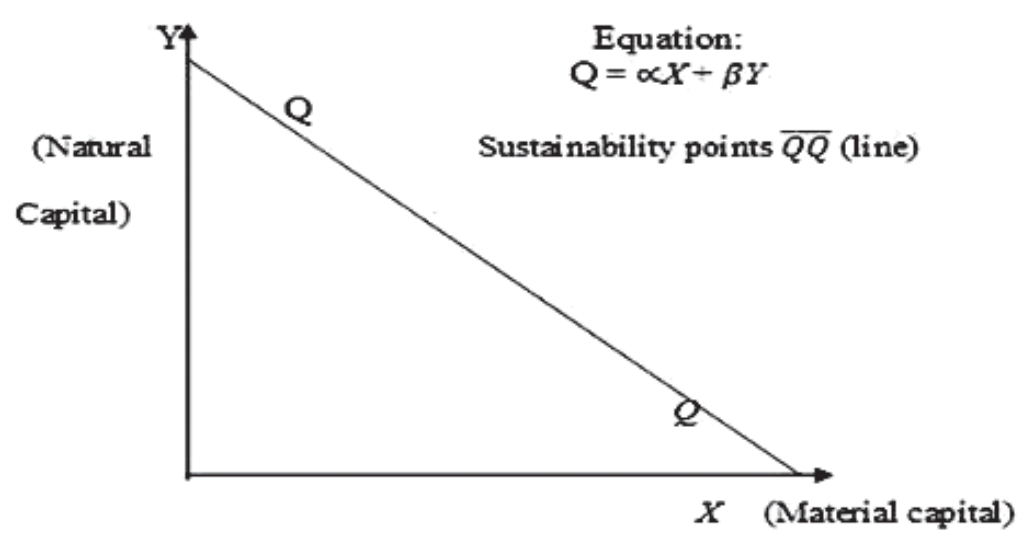

Fig.1: Substitutable resources throughout the line

Y

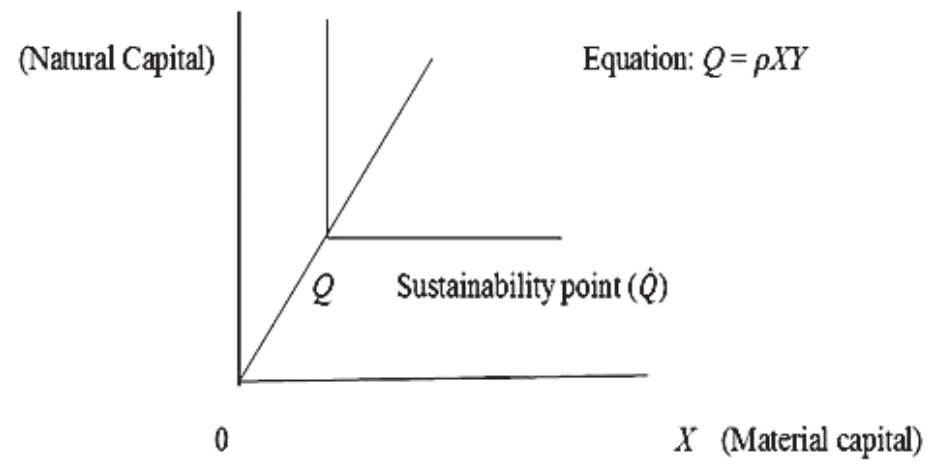

Fig.2: Substitutable resources in a fixed rate 
Sustainable and long lasting development is possible only if due attention is given for natural capital as equal as traditional resources (physical capital and labor) in planning, organizing and managing resources. In deriving his sustainable development theory, Herman Daly, mentioned that there are two principles of sustainability in resource management (Daly, 1996):

1. The speed at which resources are utilized must be equal to their capacity to be regenerated.

2. The speed of production of waste must be equal to the capacity of absorption by the ecosystems into which the waste is put.

Both capacities must be treated as 'natural capital' in which if the natural capital used up but failed to maintain this capacities (regenerate and absorb) there is no possible way for sustainability (Boggia and Cortina, 2010).

According to theory of sustainable economic development of Daly, there are two ways of maintain stock of total capital viz. weak and strong sustainability:

Weak sustainability means maintaining the sum of natural capital and material capital at a constant value. According to the weak sustainability perspective, capital produced by man, and natural capital can be substitutable to each other. Consequently, constant sum of the stock must be transferred to the future generation.

According to the graph below, producers can save the stock the natural capital by producing throughout the line. Based on this assumption, there is perfect substitution between material capital and natural capital. Hence, through technological advancement and enhanced productivity the total amount of capital will be saved in order not to jeopardize the need of the successive generations. The following is its conceptual model:

According to this equation, there is a linear relationship between parameters and the process of sustainability can be feasible throughout the line at any possible combination of natural and material capital.
Strong sustainability means keeping each of material capital and natural capital at a constant value. Under this scenario, material capital and the natural capital are not substitutable to each other. Strong sustainability perspective requires the stock of both capitals must be kept intact since the availability of one component can affect the productivity of the other. "The earth and its resources are assigned to each generation as trustees, and each generation has a duty to leave an 'intact' nature (constant natural capital) to the next generation, whatever the level of well being reached may be".

According to this assumption, the capital mix of the producers is fixed and specific proportion. Maintaining this capital mix by the current producer, total stock of capital is saved and transferred to subsequent generations.

Based on the equation, sustainability can be feasible only at a fixed rational combination of natural capital and material capital in order to maintain the total stock capital.

\section{CONCLUSION}

With the existence of technological progress and high productivity along with intertemporal saving, the initial wealth can continue growing in geometric progression. This can be realized through change in the consumers' and producers' behavior. If the prevailing generation is committed to transfer at least as equal as amount of wealth they inherited; the stock of resources sustained throughout generation. Interestingly, according to this general equation, both the growth of population and stock of resources are geometric progression.

Accordingly, it reconciles the fear of scarcity regarding population pressure and resource consumption as far as all respective generations adherent to this model. However, the mechanism of transferring wealth to inter generation can be either by inheritance or/and endowment through institutions. 


\section{ACKNOWLEDGMENT}

Financial assistance provided by the Fundamental Research Grant Scheme (FRGS), on "Greening the Economy", Institute for Environment and Development (LESTARI), Universiti
Kebangsaan Malaysia (Ref. No. FRGS/1/2012/ SSO7/UKM/01/3) and "The measurement of Oil Palm Economic Potential” (Ref. No. ERGS/1/2013/ SS07/UKM/01/1)headed by Emeritus Prof. Chamhuri Siwar is gratefully acknowledged.

\section{REFERENCES}

1. Alam, M.M., Molla, R.I., Rahman, K.M., and Murad, M.W. A Paradox of the World Population Stabilization Policy, Journal of Developing Areas, 43(1), 331-340 (2009).

2. Alam, M.M., Molla, R.I., Rahman, K.M., and Murad, M.W. Declining Work-Age Population Threats to Global Economic Sustainability, International Sustainable Development Research Society (ISDRS) Newsletter, 2: 1214, USA (2011).

3. Boggia, A. and Cortina, C. Measuring sustainable development using a multicriteria model: A case study, Journal of Environmental Management , 91 : 2301-2306 (2010).

4. Cass, D. Optimum Growth in an Aggregative Model of Capital Accumulation", the Review of Economic Studies, 32(3), 233-240 (1965).

5. Daly, H.E. Towards some operational principles of sustainable development. Ecological Economics, I (4), I-6 (1989).

6. Faucheux, S., Froger, G., Noël, J.F. What Forms of Rationality for Sustainable Development? The Journal of SocioEconomics, (1), 169-209 (1995).

7. Keynes, J.M. A Tract on Monetary Reform, Macmillan and Co., limited. London, (1923).

8. Koopmans, T.C. Stationary Ordinal Utility and Impatience, Econometrica, 28: 287-309 (1960).

9. Malthus, T.R. An Essay on the Principle of Population, New York: Norton. (Originally published in 1798) (1976).

10. Marjan, W. Modeling Sustainable Development: An economy - ecology integrated model, Economic Modeling, 13 : 333-353 (1996).

11. Mebratu, D. Sustainability and sustainable development: historical and conceptual review. Environ Impact Asses Review, 18: 493-520 (1998).

12. Molla, R.I., Murad, M.W., and Alam, M.M. Development Issues, Policies and Actions: Selected Recent Works on Malaysia and Bangladesh, Perlis: Universiti Malaysia Perlis (2013).

13. Nihoul, J. Modeling Sustainable Development as a Problem in Earth Science. Mathl. Comput. Modelling, 28(10): 1-6 (1998).

14. Ramsey F.P. A Mathematical Theory of Saving, Economic Journal, 38(152): 543 (1928).

15. Rawls, J. A Theory of Justice, Cambridge, MA: Harvard University Press, (1971).

16. Ricardo, D. On the principle of political economy and taxation, Batoche Books (2001), Ontario, Canada (1817).

17. Spangenberg, J.H., Pfahl, S., Deller, K. Joachim, H. Towards indicators for institutional sustainability: lessons from an analysis of Agenda 21, Ecological Indicators, 2, 61-77 (2002).

18. Veron, R. The "New" Kerala Model: Lessons for Sustainable Development, World Development, 29(4): 601-617.

19. WCED (World Commission on Environment and Development). Our Common Future. Oxford, U.K.: Oxford University Press (1987). 